\title{
INFORME SOBRE EL CENTRO DE DOCUMENTACION KANTIANA
}

\author{
Dulce María GRANJA DE CASTRO DE PROBERT \\ Directora del Centro de Documentacion Kantiana
}

El Centro de Documentación Kantiana de la Universidad Autónoma Metropolitana es un acervo bibliohemerográfico dedicado a estudiar la filosofía de Kant y a destacar su relevancia en el pensamiento contemporáneo. Cuenta con 2.500 títulos especializados en esta área. Ofrece asesoría y atiende consultas de los usuarios. Cuenta, asimismo, con un programa de servicio social, cuya finalidad es incorporar a los estudiantes de la universidad en las tareas de investigación y publicación que desarrolla el Centro.

Desde el comienzo de sus actividades en 1992, el Centro de Documentación Kantiana ha publicado los siguientes libros:

- El Idealismo Trascendental de Kant, una interpretación y defensa

- Kant: de la Critica a la filosofia de la religión

- Kant en español

- El Neokantismo en México

- Edición critica bilingüe alemán-español de la Crítica de la razón práctica

- En la cumbre del criticismo

- Nietzsche, critico de Kant

- Tránsito de la naturaleza a la historia en la filosofia de Kant

- Vértigos argumentales: una ética de la disputa

Recientemente ha quedado concluida por completo la edición crítica bilingüe alemán-español de otra importante obra de Kant: Observaciones sobre el sentimiento de lo bello y lo sublime. Actualmente, se trabaja en dos investigaciones que habrán de dar lugar a dos libros:

- La recepción de la filosofia kantiana en el México del siglo XIX

- Vida de Kant 
Kant es quizá el filósofo moderno que más ha insistido en la importancia de la capacidad crítica como elemento crucial de la labor educativa. Asimismo, ha descrito cuidadosamente en qué consiste la tarea crítica de la filosofía, cómo ésta es indispensable en nuestra formación y cómo puede ser enseñada la actividad filosófica desde un punto de vista antidogmático. El gran pensador de Königsberg considera que el enfoque crítico es la característica suprema de la actividad filosófica, lo cual desde luego no excluye otras funciones características de la filosofía. Al mismo tiempo, señala que las tesis filosóficas han de ser consideradas, fundamentalmente, por su capacidad para ser discutidas con instrumentos racionales y por resistir un cuestionamiento riguroso y permanente. El desarrollo de la actividad filosófica depende, esencialmente, del papel de los argumentos racionales en la crítica de las pretensiones de solución de un problema.

Desde tiempos de Sócrates, una de las tareas esenciales del filósofo ha sido la formación de los seres humanos, la educación por medio de la transmisión de una actitud crítica. Si a Descartes se le llama uel padre de la filosofía moderna", hay que llamar a Kant su pedagogo. El padre da la vida al hijo, pero el pedagogo lo educa y ésta es la función de Kant en la historia del pensamiento filosófico. El pensador de Königsberg ha sido el maestro, el pedagogo, el educador, el humanizador. Kant, como Sócrates, ha contribuido de forma decisiva a la formación del ser humano y sigue haciéndolo.

Fiel a este ideal educativo característico de la filosofía kantiana y como complemento para enriquecer la formación de recursos humanos, el Centro de Documentación Kantiana ha organizado la visita de diversos investigadores, a fin de impartir seminarios o ciclos de conferencias. Entre dichos profesores visitantes cabe destacar: Henry E. Allison, Javier Muguerza, José Gómez Caffarena, Fernando Salmerón, Ernesto Garzón, Carlos Thiebaut, Reinhard Brandt, Marcelo Dascal, etcétera.

La fuerza de la obra de Kant radica, entre otros aspectos, en ser un ejemplo estimulante y eficaz de reflexión crítica y autonomía, que no sólo nos recuerda que nada es tan difícil como no engañarse a sí mismo, sino que además nos alienta para buscar nuestro propio camino. Por ello, Kant, lejos de ser el convidado de piedra en el escenario filosófico actual, es un interlocutor insoslayable en las discusiones que motivan a la filosofía contemporánea. Desde hace dos siglos, ningún filósofo puede pretender ser totalmente independiente de las enseñanzas del pensador prusiano, que nos ha mostrado la importancia de la tolerancia, la pluralidad y el sentido crítico. 
Por ello, en el año 2004 se conmemorará en todas las universidades importantes del mundo el bicentenario del fallecimiento de Immanuel Kant. En muchos lugares, en ambos lados del Atlántico, se celebrarán magnos congresos y se organizarán talleres de trabajo y visitas especiales de investigadores y estudiosos. Asimismo, verán la luz numerosas publicaciones de y sobre Kant. En el caso concreto de México, la Universidad Nacional Autónoma de México, la Universidad Autónoma Metropolitana y el Fondo de Cultura Económica, como líderes de las humanidades en el país y dada su importante tradición de publicaciones, han acordado aunar esfuerzos para poner en marcha un proyecto de impulso de la obra de y sobre Kant en ocasión de este bicentenario.

De este modo, se está trabajando en la publicación de una Biblioteca Kantiana, que consta de dos vertientes: $1 .^{\circ}$ una colección de obras de Kant, en edición crítica bilingüe alemán-español, con estudios preliminares muy detallados hechos por conocidos especialistas en la materia, así como con notas de comentario a la traducción, índices analíticos tanto temáticos como onomásticos, bibliografias muy actualizadas y «Reflexiones» correspondientes a las temáticas de la obra en cuestión. 2..$^{\circ}$ una colección de estudios sobre el pensamiento kantiano.

La Biblioteca Kantiana incluirá algunas de las encomiables traducciones directas del alemán hechas tiempo atrás, como por ejemplo las efectuadas por Manuel García Morente. En tales casos, dichas versiones serán actualizadas conforme a las exigencias académicas del momento y se les incorporarán las referencias críticas que permitan compaginar línea a línea los textos español y alemán. De ese modo, estaremos haciendo un reconocimiento a la labor de aquellos primeros traductores de la obra de Kant al español, en virtud de las cuales muchos de nosotros tuvimos nuestro primer contacto con la filosofía kantiana. A su vez, por el respeto que nos merecen dichos traductores, se revisarán cuidadosamente esas viejas pero excelentes traducciones, para evitar todas las erratas que se han acumulado con el pasar de los años y retocar y pulir algunos detalles de redacción.

Con el fin de llevar a cabo esta tarea, se ha integrado un comité académicoeditorial de la referida Biblioteca Kantiana, en cuya integración participan académicos de la Facultad de Filosofía y Letras y del Instituto de Investigaciones Filosóficas de la Universidad Nacional Autónoma de México, así como de la 
Universidad Autónoma Metropolitana. De esa forma, también está participando en el proyecto el Centro de Documentación Kantiana.

El Comité en referencia está integrado por los siguientes académicos:

Mtro. Julio Beltrán Miranda (FFL-UNAM)

Dra. ISABel CABrera Villoro (IIF-UNAM)

Dra. Dulce Maria Granja Castro (UAM)

MTRO. JOSU LANDA GOYOGANA (FFL-UNAM)

Dra. Marfa Pfa lara Zavala (UAM)

DR. EFraÍn LAZOS OCHOA (FFL-UNAM)

Dr. Gustavo Leyva MarTínez (UAM)

Dr. Carlos Pereda Failache (IIF-Unam)

Dr. Pedro Stepanenko Gutiérrez (IIF-UNAM)

Prof. Dulce Marfa Granja de Castro de Probert

Directora del Centro de Documentación Kantiana 